\title{
Physical activity and self-esteem: testing direct and indirect relationships associated with psychological and physical mechanisms
}

This article was published in the following Dove Press journal:

Neuropsychiatric Disease and Treatment

12 October 2016

Number of times this article has been viewed

\author{
Seyed Hojjat Zamani Sani' \\ Zahra Fathirezaie' \\ Serge Brand ${ }^{2}$ \\ Uwe Pühse ${ }^{3}$ \\ Edith Holsboer-Trachsler ${ }^{2}$ \\ Markus Gerber ${ }^{3}$ \\ Siavash Talepasand ${ }^{4}$ \\ 'Department of Motor Behavior, \\ Faculty of Physical Education and \\ Sport Science, University of Tabriz, \\ Tabriz, Iran; ${ }^{2}$ Psychiatric Clinics \\ of the University of Basel, Center \\ for Affective, Stress and Sleep \\ Disorders (ZASS), ${ }^{3}$ Department of \\ Sport, Exercise and Health, Sport \\ Science Section, University of Basel, \\ Basel, Switzerland; ${ }^{4}$ Department of \\ Psychology and Educational Sciences, \\ Semnan University, Semnan, Iran
}

Correspondence: Seyed Hojjat

Zamani Sani

Department of Motor Behavior, Faculty of Physical Education and Sport Science, University of Tabriz, 51666-|4766,

29 Bahman Blvd, Tabriz, Iran

Tel +98 4I 33393247

Fax +98 4I 33393258

Email hojjatzamani8@gmail.com
Abstract: In the present study, we investigated the relationship between physical activity (PA) and self-esteem (SE), while introducing body mass index (BMI), perceived physical fitness (PPF), and body image (BI) in adults ( $\mathrm{N}=264, \mathrm{M}=38.10$ years). The findings indicated that PA was directly and indirectly associated with SE. BMI predicted SE neither directly nor indirectly, but was directly associated with PPF and both directly and indirectly with BI. Furthermore, PPF was directly related to BI and SE, and a direct association was found between BI and SE. The pattern of results suggests that among a sample of adults, PA is directly and indirectly associated with SE, PPF, and BI, but not with BMI. PA, PPF, and BI appear to play an important role in SE. Accordingly, regular PA should be promoted, in particular, among adults reporting lower SE.

Keywords: physical activity, self-esteem, physical fitness, body image, adults

\section{Introduction}

Physical activity (PA) is defined as any bodily movement produced by the contraction of skeletal muscles that results in a substantial increase in energy expenditure over resting levels. ${ }^{1}$ The World Health Organization recommends that adults aged 18-64 years should engage in at least 150 minutes of moderate-intensity PA or 75 minutes of vigorous-intensity PA throughout the week, or an equivalent combination of moderate- and vigorous-intensity activity. For additional health benefits, adults should increase their moderate-intensity PA to 300 minutes per week, or equivalent. Muscle strengthening activities involving major muscle groups should be undertaken on two or more days a week. ${ }^{2}$

Both moderate- and vigorous-intensity PAs are important for physical and mental health. ${ }^{3}$ In this regard, both the scientific community and lay people claim that regular PA impacts positively on self-esteem (SE). SE can be defined as a person's evaluative judgment of the self ${ }^{4}$ and is best understood within the framework of theoretical models of the self. ${ }^{5} \mathrm{SE}$ is important for a successful and satisfying life and constitutes a fundamental aspect of psychological well-being. ${ }^{6}$ Sonstroem and Morgan's framework of PA and SE suggests that exercising is associated with global SE through perceptions of self-efficacy, physical competence, and physical acceptance. ${ }^{7}$ In line with this notion, PA has been found to be associated with higher SE among middle-aged and healthy adults. ${ }^{8,9}$ Recently, change in SE has been shown to be significantly associated with perceived athletic competence and moderate-to-vigorous PA in children. ${ }^{10}$ Moreover, two studies identified significant increases in SE following exercise 
training. ${ }^{11,12}$ Positive relationships between PA and SE have also been observed in children and adolescents. ${ }^{13}$ In an early meta-analysis, Gruber reviewed the results of 27 studies and found that, among preadolescents, PA was significantly and moderately associated with SE. ${ }^{14}$ A similar conclusion has been reached by other researchers. ${ }^{15}$ However, significant relationships have not been identified in all subsequent studies. ${ }^{16}$ Two other studies revealed that randomized controlled trials are able to improve SE at least in the short term. ${ }^{17,19}$

While Sonstroem et al showed that specific and general perceptions of physical competencies positively impact on $\mathrm{SE},{ }^{9}$ the underlying mechanisms which link PA to SE seem to be complex. ${ }^{20}$ Sonstroem et al proposed a multifactorial framework which includes both direct and indirect pathways. ${ }^{9}$ Given this background, the purpose of the present study was threefold: first, to determine how closely PA is associated with SE; second, to examine whether PA is significantly correlated with body mass index (BMI), perceived physical fitness (PPF), and body image (BI); and third, to test the fit of a theoretical model, which posits that PA is associated with $\mathrm{SE}$ both directly and indirectly (through BMI, PPF, and BI).

The following three hypotheses were tested in the present study:

- First, based on the literature presented above, ${ }^{11,12}$ we anticipated that participants who report higher PA levels would also have higher SE (Hypothesis 1).

- Second, we expected that greater PA would be associated with a more positive BI (Hypothesis 2a). BI relates to individuals' perceptions, feelings, and thoughts about their bodies. ${ }^{21}$ Taken together, a great majority of both interventional studies ${ }^{22-26}$ and correlational studies ${ }^{27-32}$ have shown PA to be positively associated with BI, a relationship that was supported in a meta-analysis. ${ }^{33,34}$ Specifically, the meta-analysis showed that, compared to nonexercisers, exercisers had a more positive BI, and that there were significant increases in BI scores following an exercise intervention. Also, BI was found to improve after 6 weeks of exercise training. ${ }^{29}$

- Also, we expected that PA would be associated with a lower BMI (Hypothesis 2b). This hypothesis is based on studies showing that BMI decreased significantly after aerobic exercise training, ${ }^{24}$ while greater PA has been found to be associated with lower BMI scores. ${ }^{35}$

- Also, we expected that PA would be associated with greater PPF (Hypothesis 2c). Abbott and Barber indicated that, compared to noninvolvement in sports, any involvement in sporting activities was associated with better bodily functioning. ${ }^{36}$ Also, a significant correlation has been reported between exercise participation and physical competence. ${ }^{37}$ Moreover, Sonstroem et al have shown that exercise in aerobic dancers is associated with positive evaluation of physical condition. ${ }^{9}$

- Third, we hypothesized that a relationship between PA and SE could be explained in terms of both direct and indirect pathways (Hypothesis 3), in the case of the latter by higher BI and PPF and lower BMI (see Hypotheses 1-2c). In particular, our model assumes a positive relation between BI and SE (Hypothesis 3a), a negative association between BMI and SE (Hypothesis 3b), and a positive association between PPF and SE (Hypothesis 3c). Hypothesis $3 \mathrm{a}$ draws on research into the relation between $\mathrm{BI}$ and SE showing higher BI to be associated with higher SE. ${ }^{38}$ BI may also predict SE, ${ }^{39}$ as higher SE has been associated with lower body dissatisfaction. ${ }^{40}$ Hypothesis $3 \mathrm{~b}$ is consistent with a claimed association between high BMI and low SE. ${ }^{41}$ Hypothesis $3 \mathrm{c}$ reflects the findings of significant intercorrelations among exercise participation, physical competence, and $\mathrm{SE},{ }^{37}$ while greater physical fitness has been linked to higher SE. ${ }^{31}$

- Finally, we expected to find a positive relationship between PPF and BI (Hypothesis 3d) and a negative relationship between BMI and BI (Hypothesis 3e). These hypotheses are based on the fact that the evaluation of one's size, weight, strength, flexibility, endurance, and other aspects of the body that determine the manner in which the body is viewed - known as PPF - are the essential components of the physical aspect of BI. For instance, Altıntaş et al found that BMI was a significant predictor of BI and SE among adolescents. ${ }^{27}$ Accordingly, they concluded that BMI and PA play an important role in body-related perceptions. Furthermore, others have found a negative relationship between $\mathrm{BI}$ and $\mathrm{BMI}{ }^{42,43}$

\section{Methods}

\section{Participants}

A total of 300 persons aged 20-60 years were selected through stratified cluster sampling of the staff and teachers of the University of Tabriz (Tabriz, Iran). Accordingly, 15 faculties and centers were selected from among the 22 existing faculties and centers of University of Tabriz. All teachers and staff members of those faculties were asked to complete a series of questionnaires described in more detail subsequently. The return rate was $88 \% ; 264$ employees (77 females) returned complete data, which could be used for further analysis. The mean age of the total sample was $\mathrm{M}=38.10$ years (standard deviation $[\mathrm{SD}]=6.71$ ). 


\section{Procedure}

The participants received general information about the main goals of the study and were informed of the voluntary basis of their participation and anonymity of data handling. Participants were asked to give their written informed consent before completing the questionnaires. The Ethical Review Board and the deputy for research and technology of University of Tabriz approved the study, which was executed in accordance with the guidelines laid down in the Declaration of Helsinki.

\section{Materials and measures}

\section{Sociodemographic and anthropometric data}

A sociodemographic and anthropometric questionnaire covered age, educational level, health and marital status, number of children, weight, and height. BMI was calculated using the following formula: weight $(\mathrm{kg}) /$ height $^{2}\left(\mathrm{~m}^{2}\right)$.

\section{Self-reported PA}

Due to limitations of taking PA questionnaires devised in developed countries and using them in the different cultural context of developing countries, ${ }^{44}$ we used a locally constructed PA questionnaire confirmed by Bahram, Shafizadeh, and Sanatkaran in order to have good content and face validity as well as good internal reliability. The questionnaire consists of ten items focusing on frequency, intensity, duration, and type of PA per week; the items are similar to those in internationally accepted and validated instruments (eg, Global Physical Activity Questionnaire and International Physical Activity Questionnaire), and correspond to the World Health Organization's recommendations for adults (18-64 years old). Typical items are: "How often do you undertake physical activity each week?" and the answers are "more than 5 days per week, $3-5$ days per week, $1-3$ days per week, no physical activity"; "In each session, how intense are your physical activities?" and the answers are "vigorousintensity activities: activities that cause large increases in breathing or heart rate, moderate-intensity activities: activities that cause small increases in breathing or heart rate, and light-intensity activities: activities that cause negligible increases in breathing or heart rate"; "How much time do you spend doing vigorous-intensity aerobic physical activity each week?" and the answers are "more than 150 minutes during the week, 75-150 minutes during the week, less than 75 minutes during the week"; "How much time do you spend in moderate-intensity aerobic physical activity each week?" and the answers are "more than 300 minutes a week, 150-300 minutes a week, less than 150 minutes a week" $($ Cronbach's alpha $=0.69)$.

\section{Self-esteem}

SE was measured by the ten-item Self-Esteem Scale, which assesses global SE. ${ }^{6}$ Although SE was designed for adolescents, other researchers have confirmed its use in the adult population..$^{45}$ In another study ${ }^{46}$ the internal consistency of the scale was found to be good (Cronbach's alpha $=0.86$ ) and its factor loadings ranged from 0.28 to 0.81 , with communalities varying between 0.08 and 0.66 . The Cronbach's alpha in the current sample was 0.74 .

\section{Perceived physical fitness}

PPF was assessed using the Perceived Physical Fitness Scale. ${ }^{47}$ The scale consists of 12 statements related to fitness on four subscales including aerobic endurance, flexibility, muscular strength, and body composition. Participants were asked to select one of five possible answers ( $1=$ strongly disagree, $2=$ disagree, $3=$ undecided, $4=$ agree, $5=$ strongly agree), which best reflects how they feel about each statement. A sum score is calculated to obtain an overall index, with higher scores reflecting higher fitness perceptions. Convergent validity of this scale was judged to be good and test-retest reliability was high $(r=0.97)$. Concurrent validity based on correlation between subscales and performance measures in younger adults was moderate to strong. ${ }^{47}$ The internal consistency in the present sample was good (Cronbach's alpha $=0.75)$.

\section{Body image}

BI was measured using the Figure Rating Scale. ${ }^{48}$ The scale comprises a set of nine figures (male figures for male respondents and female figures for female respondents) depicting individuals ranging in body shape from very thin (1) to very obese (9). Respondents were asked to indicate which figure they believed looked most like their own body. Prior studies have shown that the scale is a valid and reliable measure of BI. ${ }^{49,50}$

\section{Statistical analysis}

First, descriptive statistics were calculated. Second, Pearson's correlations were used to explore the relationship between the study variables, which provided an insight into how the various variables may affect one another and helped to identify an initial model. Third, we used path analysis, a subset of structural equation modeling, to investigate the association between SE with PA, BMI, PPF, and BI.

Although based on correlational data, path analysis provides the researcher with a multivariate (more than one dependent variable) method to estimate structurally interpretable 
terms - the direct, indirect, and total effects (DE, IE, and TE, respectively) among a set of variables - provided that an appropriate path model, that is, a theory-derived structure of the variables included, is specified. ${ }^{51}$

Parameter estimation was conducted using maximum likelihood. Maximum likelihood is a robust estimation method even for nonnormally distributed data. With large samples ( $\mathrm{N} \geq 500)$, West et al argue that a robust estimation can be expected with skewness/kurtosis coefficients below 2 and 7 , respectively. ${ }^{52}$ As is generally recommended, multiple goodness-of-fit indexes were considered when deciding how well the theoretical model fitted the empirical data. ${ }^{53}$ These included the comparative fit index (CFI) $\geq 0.95$, goodness of fit index $\geq 0.95$, normal fit index $\geq 0.95, \chi^{2} /$ $d f<5$, incremental fit index $\geq 0.95$, and root mean square error of approximation $\leq 0.08$. For all analyses, the level of significance was set at alpha $=0.05$. Descriptive and correlational analyses were performed with Statistical Package for the Social Sciences 20.0 (IBM Corporation, Armonk, NY, USA), and path analyses with LISREL 8.5 for Windows (Scientific Software International, Inc., Skokie, IL, USA).

\section{Results}

\section{Sociodemographic and anthropometric characteristics}

Table 1 gives the sociodemographic and anthropometric characteristics of the present sample. As can be seen, a majority of participants were males, with doctoral degrees, without chronic illness, and were married and nonsmokers.

Table I Demographic characteristics ( $\mathrm{N}=264$ respondents)

\begin{tabular}{lll}
\hline Characteristic & Frequency & Percentage \\
\hline Sex & 77 & 29.2 \\
$\quad$ Women & 187 & 70.8 \\
$\quad$ Men & & \\
Education & 45 & 17 \\
$\quad$ Undergraduate & 74 & 28 \\
$\quad$ Bachelor & 145 & 55 \\
$\quad$ Master, doctorate & & \\
Health status & 242 & 91.7 \\
$\quad$ Without chronic illness & 22 & 8.3 \\
$\quad$ With chronic illness & & \\
Marital status & 36 & 13.6 \\
Single & 209 & 79.2 \\
Married & 19 & 7.2 \\
Divorced & & \\
Smoking & 16 & 6.1 \\
Yes & 248 & 93.9 \\
No & & \\
\hline
\end{tabular}

\section{Descriptive statistics of the main study variables}

Table 2 gives the descriptive statistics for the study variables. The mean scores for PA $(\mathrm{M}=10.19, \mathrm{SD}=0.50)$ and PPF $(\mathrm{M}=39.39, \mathrm{SD}=4.98)$ indicated high levels of $\mathrm{PA}$ participation and high perceived fitness. The average BMI was in the overweight range $(M=25.66, S D=3.79)$, while the average $\mathrm{BI}$ was in the normal range $(\mathrm{M}=5.26, \mathrm{SD}=1.79)$ as was the mean for $\mathrm{SE}(\mathrm{M}=5.65, \mathrm{SD}=3.77)$.

\section{Bivariate correlations between the main study variables}

Table 3 provides the bivariate correlations between the study variables. Significant correlations were found between all variables. Consistent with Hypothesis 1, PA and SE were positively correlated. Consistent with Hypothesis $2 \mathrm{a}$, a negative relationship was found between PA and BI, showing that physically active participants perceived themselves to be thinner. Likewise, support was found for Hypotheses $2 b$, namely, there would be a negative relationship between PA and BMI. Moreover, a close association was observed between PA and PPF, which is in line with Hypothesis 2c.

\section{Path analysis}

In the proposed model, all four variables (PA, BMI, PPF, $\mathrm{BI})$ were specified as directly and indirectly related to SE. A small number of missing values ( $1 \%$ of the expected data) were replaced with mean values. The initial path model tested was as follows: PA was hypothesized to be related to all variables, while additionally, PA would be linked with BI and SE through BMI and PPF. In the hypothesized explanatory model for SE, it was expected that there would be significant relationships between PPF, BI, and PA, while PA would explain BI through BMI and PPF, PPF and BMI would explain SE through BI, and PA would explain SE through PPF, BMI, and BI (Table 3).

Fit indices showed that this model had a poor fit to our data $\left(\chi^{2}[1, \mathrm{~N}=264]=23.87\right.$; root mean square error of approximation $=0.29$; CFI $=0.93$; normal fit index $=0.93$ ). In the initial model, two direct paths from PA to $\mathrm{BI}(\beta=-0.01$, $P>0.05)$ and from BMI to SE $(\beta=0.08, P>0.05)$ were nonsignificant. Examination of this model indicated that it could be modified to improve the match with the data. We eliminated the two nonsignificant paths to identify a more parsimonious model (see Figure 1).

To compare the fit of different models, we examined both $\Delta \chi^{2}$ and $\Delta$ CFI statistics because Cheung and Rensvold showed that in large samples, a difference larger than 0.01 
Table 2 Descriptive statistics of the main study variables

\begin{tabular}{|c|c|c|c|c|c|c|}
\hline \multirow[t]{2}{*}{ Variable } & \multirow[t]{2}{*}{$M$} & \multirow[t]{2}{*}{ SD } & \multicolumn{4}{|l|}{ Range } \\
\hline & & & Potential & Actual & Skewness & Kurtosis \\
\hline Physical activity & 10.19 & 0.50 & $0-18$ & $8-12$ & 0.19 & 1.09 \\
\hline Self-esteem & 5.65 & 3.77 & $-10-10$ & $-10-10$ & -1.05 & 1.53 \\
\hline Body image & 5.26 & 1.79 & $1-9$ & $1-9$ & -0.15 & -0.58 \\
\hline Perceived physical fitness & 39.39 & 4.98 & $12-60$ & $28-57$ & 0.21 & 0.30 \\
\hline Body mass index & 25.66 & 3.79 & $<18.5->30$ & $17.16-40.09$ & 0.92 & 0.30 \\
\hline
\end{tabular}

Abbreviations: M, mean; SD, standard deviation.

in the CFI would indicate a meaningful change in model fit for testing measurement invariance, even when the $\Delta \chi^{2}$ is significant. ${ }^{54,55}$ Table 4 shows the goodness-of-fit statistics of all three models. The final model with significant pathways and correlations is illustrated in Figure 1.

In the final model, $27 \%$ of the variance in SE was accounted for by variance in PA, BMI, PPF, and BI, while $50 \%$ of the variance in $\mathrm{BI}$ was accounted for by $\mathrm{PA}, \mathrm{BMI}$, and PPF.

As expected, PA was closely associated with SE ( $\beta=0.42$, $P<0.001$ ), while the direct path from BMI to SE was nonsignificant. The standardized $\beta$ values of the direct paths from $\mathrm{BI}$ and PPF to SE were $-0.12(P<0.05)$ and $0.13(P<0.05)$, respectively. BMI was closely associated with $\mathrm{BI}(\beta=0.71$, $P<0.001$ ), while the direct path from PA to BI was nonsignificant. The standardized $\beta$ value of the direct path from PPF to BI was $\beta=0.11(P<0.05)$ and PA was associated with PPF $(\beta=0.53, P<0.001)$.

The TE of PA was significantly associated with SE. Also, the TE of PPF was significantly associated with SE, but there was no significant IE through BI. In addition, the TE of BMI was not significantly related to SE (Table 5). BMI was positively and significantly associated with $\mathrm{BI}$. The TE and DE of PA were also positively and significantly associated with $\operatorname{PPF}(\mathrm{DE}=0.53, P<0.001 ; \mathrm{TE}=0.53, P<0.001)$. The TE and $\mathrm{DE}$ of $\mathrm{PA}$ were also positively and significantly associated with SE (DE $=0.42, P<0.001$; TE $=0.502, P<0.001)$, and

Table 3 Zero-order correlations between the main study variables

\begin{tabular}{lllll}
\hline Variable & $\mathbf{I}$ & $\mathbf{2}$ & $\mathbf{3}$ & $\mathbf{4}$ \\
\hline I. PA & & & & \\
2. BMI & $-0.24^{* *}$ & & & \\
3. PPF & $0.53^{* *}$ & $0.121^{*}$ & & \\
4. BI & $-0.12^{*}$ & $0.7 I^{* *}$ & $0.19^{* *}$ & \\
5. SE & $0.50^{* *}$ & $-0.14^{*}$ & $0.33^{* *}$ & $-0.15^{*}$ \\
\hline
\end{tabular}

Notes: $* P<0.05 ; * * P<0.01$.

Abbreviations: $\mathrm{BI}$, body image; BMI, body mass index; PA, physical activity; PPF, perceived physical fitness; SE, self-esteem. there was a positive IE through BMI, PPF, and $\mathrm{BI}(\mathrm{IE}=0.084$, $P<0.05)$.

\section{Discussion}

The aim of the present study was to investigate the direct and indirect relationships between PA and SE, explained through BMI, PPF, and BI. The key finding was that PA was associated both directly (greater reported PA was associated with higher SE) and indirectly (higher PA linked with a higher SE through lower BI and BMI and higher PPF and SE) with SE.

Two hypotheses were formulated and these are now considered in turn.

Our first hypothesis was that PA would be directly associated with SE, and this was confirmed. Accordingly, the present results are consistent with previous findings, $, 9,913,56,57$ but contrast with those studies which failed to report an association between PA and SE. ${ }^{16,41}$ To explain these inconsistencies, we propose the following explanations. First, methodological issues such as different tools to assess PA and SE, sampling differences (including sample sizes, age, and sex distribution), as well as possible further latent, but unassessed variables might have contributed to this heterogeneous picture of the association between PA and SE. ${ }^{58}$

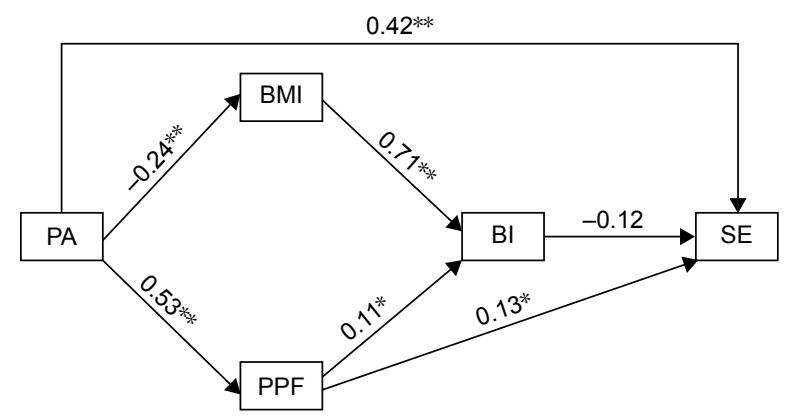

Figure I The final model of the relationships among the study variables based on weighted standardized path coefficients.

Notes: $* P<0.05 ; * * P<0.01$.

Abbreviations: BI, body image; BMI, body mass index; PA, physical activity; PPF, perceived physical fitness; SE, self-esteem. 
Table 4 Goodness-of-fit indices for the models tested

\begin{tabular}{|c|c|c|c|c|c|c|}
\hline Model & $\frac{\chi^{2}}{d f}$ & RMSEA & NFI & IFI & CFI & GFI \\
\hline Initial model (model I) & 23.87 & 0.30 & 0.93 & 0.94 & 0.93 & 0.96 \\
\hline Model 2 (path from BMI to SE removed) & 12.48 & 0.21 & 0.93 & 0.93 & 0.94 & 0.96 \\
\hline Model 3 (path from PA to BI removed) & 8.35 & 0.16 & 0.95 & 0.95 & 0.95 & 0.96 \\
\hline Accepted reference value & $<5.0$ & $\leq 0.10$ & $\geq 0.95$ & $\geq 0.95$ & $\geq 0.95$ & $\geq 0.95$ \\
\hline
\end{tabular}

Abbreviations: BI, body image; BMI, body mass index; CFI, comparative fit index; GFI, goodness-of-fit index; IFI, incremental fit index; NFI, normal fit index; PA, physical activity; RMSEA, root mean square error of approximation; SE, self-esteem.

Second, there is evidence that fitness change might not be necessary for enhanced SE; Biddle et al observed that perceptions of health, physical competence, fitness, and BI may become more positive simply because there is a feeling that the body is improving through exercise..$^{59}$

Our second hypothesis, which also addressed some of the issues regarding methodological variations across previous studies, ${ }^{7,28}$ was that the association between PA and SE might be explained indirectly, that is through factors such as PPF, $\mathrm{BI}$, and BMI. We found some support for this hypothesis. As depicted in Figure 1 and Tables 3 and 4, PA was indirectly associated with SE through PPF, BI, and BMI. Again, this pattern of results is in accordance with Sonstroem et al, ${ }^{9}$ but is at odds with other studies, ${ }^{16,41}$ which did not find any effect of aerobic exercise on SE or a significant association between PA and SE in adolescents. It seems that subject characteristics and type of PA may affect SE improvement. ${ }^{59}$ Also, Biddle et al found some indications that muscular fitness reflected in improved tone or strength can have a more rapid and powerful sensory effect than cardiovascular change. ${ }^{59}$ Again, we believe that the present pattern of results expand on previous research in showing that the relation between

Table 5 Decomposition of effects from the path analysis

\begin{tabular}{clll}
\hline Effect & Direct & Indirect & Total \\
\hline $\begin{array}{c}\text { On BMI } \\
\text { Of PA }\end{array}$ & $-0.239^{* * *}$ & & $-0.239 * * *$ \\
On PPF & & & \\
Of PA & $0.531^{* * *}$ & & $0.531 * * *$ \\
On BI & & & \\
Of PA & & $-0.110^{*}$ & $-0.110^{*}$ \\
Of BMI & $0.707^{* * *}$ & & $0.707^{* * *}$ \\
Of PPF & $0.111^{* *}$ & & $0.111^{* *}$ \\
On SE & & & \\
Of PA & $0.417^{* * *}$ & $0.084^{*}$ & $0.502^{* * *}$ \\
Of BMI & & -0.088 & -0.088 \\
Of PPF & $0.133^{*}$ & -0.014 & $0.119^{*}$ \\
Of BI & $-0.124^{*}$ & & $-0.124^{*}$ \\
\hline
\end{tabular}

Notes: $\mathrm{N}=264 ; * \mathrm{P}<0.05 ; * * \mathrm{P}<0.01$; $* * * \mathrm{P}<0.00$ I.

Abbreviations: Bl, body image; BMI, body mass index; PA, physical activity; PPF, perceived physical fitness; SE, self-esteem.
$\mathrm{PA}$ and SE is complex and dependent on further key factors such as BMI, BI, and PPF.

However, these complex interrelations demand additional explanation, and research on the individual relations among PA, SE, BMI, BI, and PPF are helpful in this regard. For instance, previous research has revealed a positive association between increased PA and higher PPF. ${ }^{9,36,37}$ Furthermore, as regards the association between PA and $\mathrm{BI}$, our findings are in line with those from different types of research such as interventional ${ }^{22-26}$ and correlational studies ${ }^{27,32}$ and with a meta-analysis. ${ }^{33}$ The same holds true for the relation between PA, BI, and BMI; Duncan et al found BMI decreased significantly after 6 weeks of aerobic exercise training. ${ }^{24}$ Nevertheless, Rote et al found no relationship between lifestyle PA and BI in women. ${ }^{60}$ Also, Kaminsky and Dewey found that higher levels of PA were not associated with a more positive BI. ${ }^{41}$ It seems likely that some components of PA (ie, type, frequency, intensity, and time) can affect this relationship. ${ }^{60,61}$ In this regard, it is possible that several types of PA are effective in changing self-perceptions, but there is most evidence to support the effects of aerobic exercise and weight training, with weight training having the greater effectiveness in the short term. ${ }^{62}$

Next, as regards the link between BI and SE, the current findings are consistent with other studies reporting a significant relationship between these variables. ${ }^{31,38-40}$ It seems that the direction of these relationships is dependent on different scales used in BI assessment. In the present study, we used the Figure Rating Scale, in which very high scores indicate very obese conditions among people; so, the negative relationship was predictable between these two variables. Also, we found a negative relationship between BMI and SE. In this regard, higher BMI has been found to be associated with lower SE. ${ }^{41}$

In the path analysis, it was shown that PA had a DE on BMI (negatively) and on PPF and SE (positively), while it had IE on BI (negatively) and SE (positively). In addition, we found that BMI was directly related to BI. Also, PPF had DE on BI and SE (positively). Finally, BI had a DE on SE (negatively). Previous theoretical models were partially 
supported in that not only involvement in PA had a direct effect on positive outcomes, but also because the influences of key physical and psychological characteristics were important. It seems that PA involvement is associated with higher SE levels. Yet, other factors have vital effects on the association between PA and SE. This finding is consistent with past research pointing to the importance of other factors in the association between PA and SE. 7,28

We also found that BMI has no DE or IE on SE. But BMI had a DE on BI and BI had a DE on SE. It seems that BMI as a physical factor cannot affect SE, directly, but it can influence $\mathrm{BI}$, and the latter can, in turn, improve SE. This finding was consistent with other studies that have reported positive correlations between exercise participation, physical competence, and $\mathrm{SE},{ }^{37}$ and the relationship between $\mathrm{SE}$ and $\mathrm{BI}$, and predictability of SE through BI. ${ }^{31,39}$ Also, our results were consistent with Altıntaş et al, ${ }^{27}$ who indicated that BMI can influence BI.

It was found that PPF has a DE on BI. This finding is consistent with other studies indicating that perceived changes in fitness (eg, perceived improvement in weight loss, muscle tone, strength, and endurance) might trigger improvement in BI. This finding suggests that the extent to which people believe their body has changed as a result of their exercise behavior has an effective impact on BI. ${ }^{61}$ Indeed, when exercisers perceive a meaningful transformation in their body, BI is more likely to improve.

These results suggest that it is not PA involvement per se that leads to feeling more positively about the body. Rather, PA provides the opportunity to develop strength and muscle tone, and to improve flexibility, coordination, and balance. Consistent with self-concept theory, ${ }^{56}$ those who feel more physically competent also have a better BI. Accordingly, these findings demonstrate the importance of physical competence as a potential mechanism through which positive BI can be developed. ${ }^{28}$

Despite the new findings, several limitations warn against an overgeneralization of the results. First, the study design was cross-sectional, which, strictly speaking, precludes conclusions about the direction of causal relationships between individual variables. Nevertheless, based on theoretical frameworks, we believe that PA is related to SE both directly and indirectly, and the fit of the final model (Figure 1) is consistent with this. However, we acknowledge that reverse causality is also possible in the sense that SE has an impact on PA levels. Second, we relied entirely on self-reports; it would have been valuable to have also measured PA objectively, by means of actigraphs or similar devices, and this could have enhanced the reliability and validity of the data on PA. Third, the present pattern of results might have emerged due to further, but unassessed factors, which might have biased two or more dimensions in the same or in the opposite directions. For example, it was shown that there is a significant positive association between the PA level and mental health. ${ }^{3,63}$ However, in the present study, we did not evaluate any mental health variable, which could have had multiple relationships with PA and SE. Fourth and last, the sample consisted of university staff members; accordingly, a systematic sample bias is possible.

\section{Conclusion}

Among a sample of adult university staff members, increased PA influenced SE directly and indirectly. Furthermore, BMI, PPF, and BI impacted independently on the association between PA and SE. Therefore, it seems that PA interventions could consider these variables as motivating and mediating factors. This is very important in that practitioners may wish to place greater emphasis on the perception of physical fitness, changes in BMI, and improving BI, when trying to increase PA and its consequences, such as SE. These variables can be measured and compared across different times of PA interventions.

\section{Acknowledgment}

We thank Nick Emler (University of Surrey, Surrey, UK) for proofreading the manuscript. The entire study has been performed without external funding.

\section{Disclosure}

All authors declare no conflicts of interest in this work.

\section{References}

1. Caspersen CJ, Powell KE, Christenson GM. Physical activity, exercise, and physical fitness: definitions and distinctions for health-related research. Public Health Rep. 1985;100(2):126-131.

2. Who.int [homepage on the Internet]. Geneva: Media centre, Physical activity, Fact sheet [Reviewed June 2016]. Available from: http://www. who.int/en/. Accessed August 14, 2016.

3. Biddle SJH, Mutrie N. The Psychology of Physical Activity. London, Routledge; 2008.

4. Rosenberg, M. Conceiving the Self. New York: Basic Books; 1979.

5. Levy SS, Ebbeck V. The exercise and self-esteem model in adult women: the inclusion of physical acceptance. Psychol Sport Exerc. 2005;6(5): $571-584$.

6. Rosenberg, M. Society and the Adolescent Self-Image. Princeton, NJ: Princeton University Press; 1965.

7. Sonstroem RJ, Morgan, WP. Exercise and self-esteem: rationale and model. Med Sci Sports Exerc. 1989;21(3):329-337.

8. Alfermann D, Stoll O. Effects of physical exercise on self-concept and well-being. Int J Sport Psychol. 2000;31(1):47-65.

9. Sonstroem RJ, Harlow LL, Josephs L. Exercise and self-esteem: validity of model expansion and exercise associations. J Sport Exerc Psychol. 1994;16(1):29-42. 
10. Noordstar JJ, Van der Net J, Jak S, Helders PJ, Jongmans MJ. Global self-esteem, perceived athletic competence, and physical activity in children: a longitudinal cohort study. Psychol Sport Exerc. 2016;22: 83-90.

11. Barton J, Griffin M, Pretty J. Exercise-, nature-and socially interactivebased initiatives improve mood and self-esteem in the clinical population. Perspect Public Health. 2012;132(2):89-96.

12. Legrand FD. Effects of exercise on physical self-concept, global self-esteem, and depression in women of low socioeconomic status with elevated depressive symptoms. J Sport Exerc. 2014;36(4): 357-365.

13. Guinn B, Semper T, Jorgensen L. Mexican American female adolescent selfesteem: the effect of body image, exercise behaviour and body fatness. Hispanic J Behav Sci. 1997;19(4):517-526.

14. Gruber J. Physical activity and self esteem development in children: a meta-analysis. In: Stull G, Eckern H, editors. Effects of Physical Activity on Children. Champaign, IL: Human Kinetics; 1986:330-348.

15. Calfas KJ, Taylor WC. Effects of physical activity on psychological variables in adolescents. Pediatr Exerc Sci. 1994;6:406-423.

16. Walters S, Martin JE. Does aerobic exercise really enhance self-esteem in children? A prospective evaluation in 3rd-5th graders. J Sport Behav. 2000;23(1):51-60.

17. Ekeland E, Heian F, Hagen K, Coren E. Can exercise improve selfesteem in children and young people? A systematic review of randomised controlled trials. Br J Sports Med. 2005;39(11):792-798.

18. Ahn S, Fedewa AL. A meta-analysis of the relationship between children's physical activity and mental health. J Pediatr Psychol. 2011; 36(4):385-397.

19. Biddle SJH, Asare M. Physical activity and mental health in children and adolescents: a review of reviews. Br J Sports Med. 2011;45(11): 886-895.

20. Van de Vliet P, Knapen J, Onghena P, et al. Relationships between selfperceptions and negative affect in adult Flemish psychiatric in-patients suffering from mood disorders. Psychol Sport Exerc. 2002;3(4):309-322.

21. Grogan S. Body Image: Understanding Body Dissatisfaction in Men, Women and Children. London, New York: Routledge; 1999.

22. Burgess G, Grogan S, Burwitz L. Effects of a 6-week aerobic dance intervention on body image and physical self-perceptions in adolescent girls. Body Image. 2006;3(1):57-66.

23. Carraça EV, Markland D, Silva MN, et al. Physical activity predicts changes in body image during obesity treatment in women. Med Sci Sports Exerc. 2012;44(8):1604-1612.

24. Duncan MJ, Nakeeb Y, Nevill AM. Effects of a 6-week circuit training intervention on body esteem and body mass index in British primary school children. Body Image. 2009;6(3):216-220.

25. Lindwall M, Lindgren EC. The effects of a 6-month exercise intervention programme on physical self-perceptions and social physique anxiety in non-physically active adolescent Swedish girls. Psychol Sport Exerc. 2005;6(6):643-658.

26. Vocks S, Hechler T, Rohrig S, Legenbauer T. Effects of a physical exercise session on state body image: the influence of pre-experimental body dissatisfaction and concerns about weight and shape. Psychol Health. 2009;24(6):713-728.

27. Altıntaş A, Aşç $\mathrm{F}$, Kin-İşler A, et al. The role of physical activity, body mass index and maturity status in body-related perceptions and self-esteem of adolescents. Ann Hum Biol. 2014;41(5):395-402.

28. Greenleaf C, Boyer EM, Petrie TA. High school sport participation and subsequent psychological well-being and physical activity: the mediating influences of body image, physical competence, and instrumentality. Sex Roles. 2009;61(9-10):714-726.

29. Griffin M, Kirby S. The effect of gender in improving body image and self-esteem. Athletic Insight. 2007;9(3):83-92.

30. Homan KJ, Tylka TL. Appearance-based exercise motivation moderates the relationship between exercise frequency and positive body image. Body Image. 2014;11(2):101-108.

31. Lowery SE, Kurpius SER, Befort C, et al. Body image, self-esteem, and health-related behaviors among male and female first year college students. J Coll Stud Dev. 2005;46(6):612-623.
32. Reel JJ, Greenleaf C, Baker WK, et al. Relations of body concerns and exercise behavior: a meta-analysis. Psychol Rep. 2007;101(3): 927-942.

33. Campbell A, Hausenblas HA. Effects of exercise interventions on dody image: a meta-analysis. J Health Psychol. 2009;14(6):780-793.

34. Hausenblas HA, Fallon EA. Exercise and body image: a meta-analysis. Psychol Health. 2006;21(1):33-47.

35. Du H, Bennett D, Li L, et al. Physical activity and sedentary leisure time and their associations with BMI, waist circumference, and percentage body fat in 0.5 million adults: the China Kadoorie Biobank study. Am J Clin Nutr. 2013;97(3):487-496.

36. Abbott BD, Barber BL. Differences in functional and aesthetic body image between sedentary girls and girls involved in sports and physical activity: does sport type make a difference? Psychol Sport Exerc. 2011;12(3):333-342.

37. Baldwin MK, Courneya KS. Exercise and self-esteem in breast cancer survivors: an application of the exercise and self-esteem model. J Sport Exerc Psychol. 1997;19(4):347-358.

38. Oney CN, Cole ER, Sellers RM. Racial identity and gender as moderators of the relationship between body image and self-esteem for African Americans. Sex Roles. 2011;65(7-8):619-631.

39. Casanova MD. The Relationship of Body Image Satisfaction and SelfEsteem Among Southern California College Women: A Cross-Cultural Study. Chicago School of Professional Psychology, 2014. Retrieved from: http://gradworks.umi.com/36/82/3682852.html

40. Mellor D, Fuller-Tyszkiewicz M, McCabe MP, Ricciardelli LA. Body image and self-esteem across age and gender: a short-term longitudinal study. Sex Roles. 2010;63(9-10):672-681.

41. Kaminsky LA, Dewey D. The association between body mass index and physical activity, and body image, self-esteem and social support in adolescents with type 1 diabetes. Can J Diabetes. 2014;38(4):244-249.

42. McCabe MP, Ricciardelli LA. Sociocultural influences on body image and body changes among adolescent boys and girls. J Soc Psychol. 2003;143(1):5-26.

43. Morano M, Colella D, Capranica L. Body image, perceived and actual physical abilities in normal-weight and overweight boys involved in individual and team sports. $J$ Sport Sci. 2011;29(4):355-362.

44. Shephard RJ. Limits to the measurement of habitual physical activity by questionnaires. Br J Sports Med. 2003;37(3):197-206.

45. Goldsmith RE. Dimensionality of the Rosenberg self-esteem scale. J Soc Behav Pers. 1986;1(2):253-264.

46. Gray-Little B, Williams VS, Hancock TD. An item response theory analysis of the Rosenberg Self-Esteem Scale. Pers Soc Psychol B. 1997; 23(5):443-451.

47. Tinakon W, Nahathai W. A comparison of reliability and construct validity between the original and revised versions of the rosenberg self-esteem scale. Psychiatry Investig. 2012;9(1):54-58.

48. Abadie BR. Construction and validation of a perceived physical fitness scale. Percept Mot Skills. 1988;67(3):887-892.

49. Stunkard A, Sorensen T, Schulsinger F. Use of the danish adoption register for the study of obesity and thinness. In: Kety SS, Rowland LR, Sidman RL, Matthysse SW, editors. The Genetics of Neurological and Psychiatric Disorders, New York: Raven Press; 1983:115-120.

50. Cardinal TM, Kaciroti N, Lumeng JC. The figure rating scale as an index of weight status of women on videotape. Obesity. 2006;14(12): 2132-2135.

51. Scagliusi FB, Alvarenga M, Polacow VO, et al. Concurrent and discriminant validity of the Stunkard's figure rating scale adapted into Portuguese. Appetite. 2006;47(1):77-82.

52. West SG, Finch JF, Curran PJ. Structural equation models with nonnormal variables: problems and remedies. In: Hoyle RH, editors. Structural Equation Modeling: Concepts, Issues, and Applications, Thousand Oaks, CA: Sage Publications; 1995:56-75.

53. Mueller RO. Basic Principles of Structural Equation Modeling: An Introduction to LISREL and EQS. Heidelberg, Germany: Springer Science \& Business Media; 1996.

54. McDonald RP, Ho MHR. Principles and practice in reporting structural equation analyses. Psychol Methods. 2002;7(1):64-82. 
55. Cheung GW, Rensvold RB. Evaluating goodness of fit indexes for testing measurement invariance. Struct Equ Modeling. 2002;9(2):233-255.

56. Lindwall M, Asci H, Hagger MS. Factorial validity and measurement invariance of the revised physical self-perception Profile (PSPP-R) in three countries. Psychol Health Med. 2011;16(1):115-128.

57. Marsh HW, Perry C, Horsely C, Roche L. Multidimensional selfconcepts of elite athletes: how do they differ from the general population? J Sport Exerc Psychol. 1995;17(1):70-83.

58. Liu M, Wu L, Ming Q. How does physical activity intervention improve self-esteem and self-concept in children and adolescents? Evidence from a meta-analysis. PLoS One. 2015;10(8):e0134804.

59. Fox KR. The effects of exercise on self-perceptions and self-esteem. In: Biddle SJH, Fox KR, Boutcher SH, Faulkner G, editors. Physical Activity and Psychological Well-Being. London: Routledge; 2000.
60. Rote AE, Swartz AM, Klos LA. Associations between lifestyle physical activity and body image attitudes among women. Women Health. 2013;53(3):282-297.

61. Biddle SJH, Fox KR, Boutcher SH, Faulkner G. The way forward for physical activity and the promotion of psychological well-being. In: Biddle SJH, Boutcher SH, editors. Physical Activity and Psychological Well-Being, London: Routledge; 2000:154-168.

62. Martin Ginis KA, Bassett RL. Exercise and changes in body image. In: Cash TF, Smolak L, editors. Body image: A Handbook of Science, Practice, and Prevention. 2nd ed. New York: Guilford Press; 2012: 378-387.

63. Ho FK, Louie LH, Chow CB, Wong WH, Ip P. Physical activity improves mental health through resilience in Hong Kong Chinese adolescents. BMC Pediatr. 2015;15(1):15-48.
Neuropsychiatric Disease and Treatment

\section{Publish your work in this journal}

Neuropsychiatric Disease and Treatment is an international, peerreviewed journal of clinical therapeutics and pharmacology focusing on concise rapid reporting of clinical or pre-clinical studies on a range of neuropsychiatric and neurological disorders. This journal is indexed on PubMed Central, the 'PsycINFO' database and CAS,

\section{Dovepress}

and is the official journal of The International Neuropsychiatric Association (INA). The manuscript management system is completely online and includes a very quick and fair peer-review system, which is all easy to use. Visit http://www.dovepress.com/testimonials.php to read real quotes from published authors.

Submit your manuscript here: http://www.dovepress.com/neuropsychiatric-disease-and-treatment-journal 